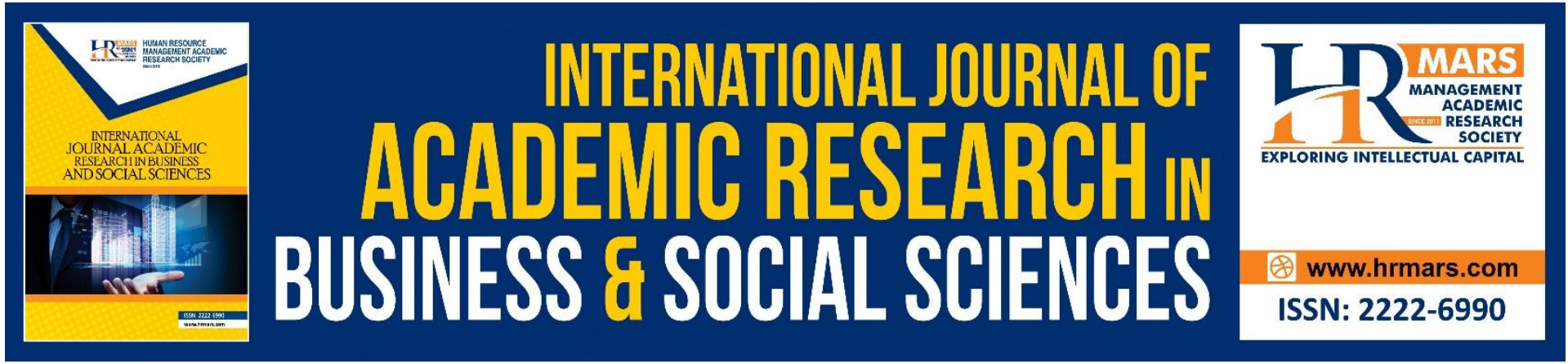

\title{
The Effectiveness of Enrichment Activities Program based on Educational Techniques in Developing Attitudes towards Mathematics among Third Graders in Jordan
}

Haya Abed Ahmad Homedan, Nashaat Baioumy, Tasnim Binti Mohd Annuar

To Link this Article: http://dx.doi.org/10.6007/IJARBSS/v11-i6/10368

DOI:10.6007/IJARBSS/v11-i6/10368

Received: 21 April 2021, Revised: 24 May 2021, Accepted: 12 June 2021

Published Online: 27 June 2021

In-Text Citation: (Homedan et al., 2021)

To Cite this Article: Homedan, H. A. A., Baioumy, N., \& Annuar, T. B. M. (2021). The Effectiveness of Enrichment Activities Program based on Educational Techniques in Developing Attitudes towards Mathematics among Third Graders in Jordan. International Journal of Academic Research in Business and Social Sciences, 11(6), 1403-1417.

\section{Copyright: (c) 2021 The Author(s)}

Published by Human Resource Management Academic Research Society (www.hrmars.com)

This article is published under the Creative Commons Attribution (CC BY 4.0) license. Anyone may reproduce, distribute, translate and create derivative works of this article (for both commercial and non-commercial purposes), subject to full attribution to the original publication and authors. The full terms of this license may be seen at: http://creativecommons.org/licences/by/4.0/legalcode

Vol. 11, No. 6, 2021, Pg. 1403 - 1417

Full Terms \& Conditions of access and use can be found at http://hrmars.com/index.php/pages/detail/publication-ethics 


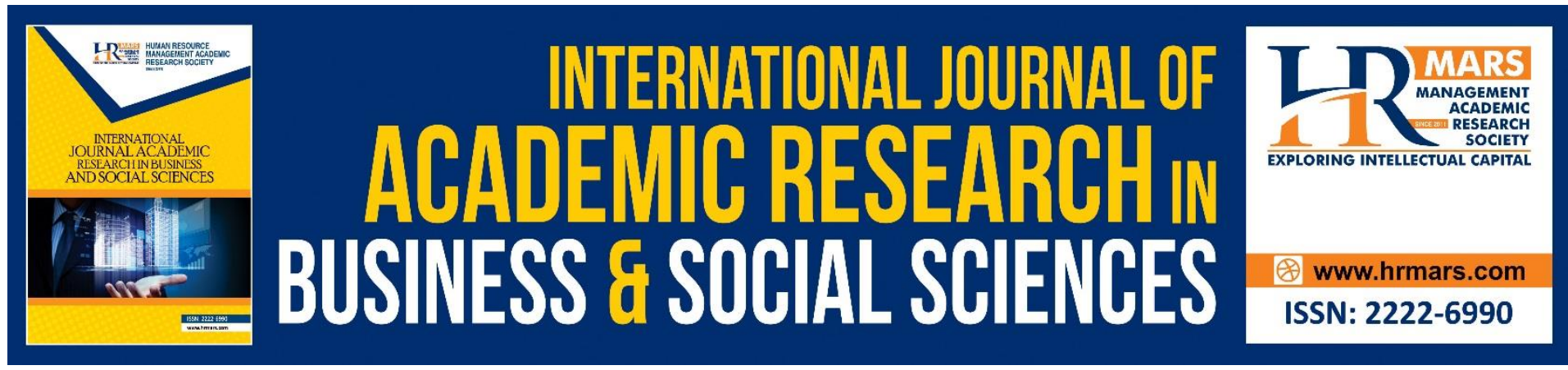

\title{
The Effectiveness of Enrichment Activities Program based on Educational Techniques in Developing Attitudes towards Mathematics among Third Graders in Jordan
}

\author{
Haya Abed Ahmad Homedan, Nashaat Baioumy, Tasnim Binti \\ Mohd Annuar \\ Faculty of Islamic Contemporary Studies, University Sultan Zainal Abidin \\ Email: nashaatbaioumy@unisza.edu.my
}

\begin{abstract}
The study aimed to identify the effectiveness of enrichment activities program based on educational techniques in developing attitudes towards mathematics among third-grade students in Jordan. To achieve the goal of the study, the researcher followed the descriptive and quasi-experimental approach to obtain the results. The study population consisted of third-grade students in government schools affiliated with the Directorate of Education in Jerash Governorate. The study sample consisted of (60) male and female third-grade students, which were chosen by the random cluster method, and a questionnaire was built to determine the quality standards of the unit outputs of collecting numbers within 9999 and subtracting them, and measure the attitude of third-grade students towards mathematics. Appropriate statistical analyzes were conducted and quantitative results were extracted through arithmetic averages and standard deviations. The most important results shown by the study were: There is a statistically significant difference at the level of statistical significance $(0.05)$ between the outcomes of the experimental and control groups in the students' attitude towards mathematics in the unit of collecting numbers within 9999 and subtracting them for the third-grade students in Jordan. These differences are attributed to the experimental group. The study contributed to building an enrichment activities program based on educational techniques and revealing its effectiveness in developing third-graders attitudes towards mathematics in Jordan.
\end{abstract}

Keywords: Effectiveness, Enrichment Activities Program, Educational Techniques, Attitudes, Third Grade.

\section{Introduction}

Contemporary scientific and technological progress has contributed to a comprehensive change in most areas of economic, social, political, cultural, and educational life. Therefore, the countries of the world have been keen to keep pace with this development and respond to the new requirements of society in general and individual in particular, because education is the mainstay of change and the tool that prepares today's generation 
for tomorrow's world. Countries are racing to develop their educational systems to keep pace with the spirit of times; because the outcomes of these systems will greatly be reflected in all fields. Therefore, the development of societies depends on the development of their educational systems. Therefore, the study sought to encourage the educational process to work on preparing a generation capable of facing various problems and challenges and achieving the desired sustainable development in the educational process.

The use of educational technologies in education is one of the important and contemporary topics, and everyone has realized that nations' destiny depends on the creativity of their children, and the extent of their challenge to change problems and demands. Education occupies a prominent position within the framework of societal shift. Education is one of the most important pillars covered by the winds of change and renewal. Educational technologies in teaching have greatly developed in recent years, and this is evident through the developmental stages they have gone through, which were accompanied by a change in their names until they are now known as educational technology, i.e. educational techniques (Al-Anzi, 2018).

Educators suggest focusing on educational technology and enrichment activities programs, in particular, the one that takes into account students' attitudes, tendencies and interests, raises their motivation towards learning, develops their thinking skills, and emphasizes the positive role of technology in enrichment activities that develop students' cognitive variables, such as divergent and lateral thinking abilities, and educational attainment (Gulla, 2017).

\section{Problem of the Study}

Today's world faces many challenges and difficulties. The reason for this is the rapid scientific and technological revolution in all fields of life, the rapid scientific openness through communication and information networks that removed all obstacles and facilitated communication between peoples. The globalization phenomenon that moved us from focusing on the local and national to the global community, and the changes that have occurred in all aspects of social, economic and cultural life, make it necessary for educational organizations to adopt modern educational methods to achieve their objectives and face most of the challenges and difficulties. Scientific and technological development has enriched the educational process with many modern and innovative educational techniques which can be used to provide appropriate experiences for learners and through which the student is prepared with a high degree of efficiency and knowledge that qualifies him to face the various contemporary challenges and make him able to effectively use modern technology in education (Al-Hayla, 2001).

The problem of the study lies in the researcher's experience, as she works as a teacher in government schools, and is familiar with the conditions of education, as she felt that there is a decline in the students' academic achievement, weakness in their attitudes towards mathematics, and weakness in mathematical thinking and problem solving, in addition to the negative attitudes they hold towards mathematics and the prevalence of traditional methods of teaching it. This was clearly demonstrated by the International Mathematics Tests (TIMSS) for the year 2007, which was similar to the 2003 result, which again showed weakness in students' attitudes towards mathematics and in educational outcomes, especially technical education outcomes. This is in addition to what was revealed by the Ministry of Education and the National Center for Human Resources Development reports in Jordan, that the level of basic stage students' attitudes towards mathematics is less than the educationally 
acceptable level, and that mathematics teachers in Jordan generally do not direct their teaching to enrichment activities based on educational technology. It would have been better if Jordanian mathematics curriculum outlines include objectives that emphasize the need to pay attention to students' attitudes towards learning Arabic and positively change their attitudes towards it.

Jordan, like other countries in the world, is constantly striving to develop its educational system by relying on excellence and quality, investing human resources and available opportunities, enhancing the ability to research, and developing individuals' contribution to a renewable knowledge-based economy, as it seeks to be on the map of developed and modern countries prepared for human competencies capable of competition (Ministry of Education, 2017).

Given the lack of studies and research in this field, the importance of this study comes in an attempt to reveal the effectiveness of enrichment activities program based on educational techniques in developing attitudes and trends towards mathematics among third graders in Jordan.

\section{Study Questions}

1. What are the quality standards of the unit outputs of collecting numbers within 9999 and subtracting them for third graders mathematics in Jordan?

2. What is the effectiveness of applying the proposed enrichment activities program based on educational techniques in developing students' attitudes towards mathematics in the unit of collecting numbers within 9999 and subtracting them to third graders in Jordan?

\section{Objectives of the Study}

1. Building a list of quality standards for unit outputs of collecting numbers within 9999 and putting them for third graders mathematics in Jordan.

2. Revealing the effectiveness of the proposed enrichment activities program based on educational techniques in developing students' attitudes towards mathematics in the unit of collecting numbers within 9999 and putting them up for third graders in Jordan.

\section{Importance of the Study}

The importance of the current study is evident by finding a modern method for teaching mathematics using enrichment activities program based on educational techniques. The results of the study also contribute to directing the attention of those in charge of the educational process and decision-makers to the importance of introducing educational technology programs in the educational process, in order to reduce the low level of academic achievement of mathematics students, and shedding light on the importance of education using educational technologies and their ability to take into account individual differences among students, and develop their positive attitudes towards learning mathematics in a fun atmosphere, away from boredom, fear and tension during the mathematics study.

\section{Limitations of the Study}

This research is objectively limited to the following:

Objective Limits: The current study deals with the knowledge of the proposed program effectiveness in developing students' attitudes towards mathematics in the unit of collecting numbers within 9999 and subtracting them to third graders in Jordan. 
Spatial Limits: the study was limited to two primary schools in Jerash Governorate / Jordan.

Time Limits: The study implementation time was limited to the first semester of the year 2019/2020.

4- Human limits: the study was limited to male/female third-grade students.

\section{Terminology of the Study}

- Effectiveness: It is the effect size that is statistically indicative between the pre and postapplication of the test that was designed to measure the effect size (Abu Mandeel, 2006).

The researcher defines it procedurally: It is the positive effect of using enrichment activities program based on educational techniques in developing third-grade attitudes towards mathematics, to improve their academic achievement and provide them with mental skills and positive attitudes.

Enrichment Activities Program: These are all activities and programs carried out by students inside and outside the school according to their abilities and inclinations, which helps them in building an integrated and balanced social personality in all its social, physical, mental and emotional aspects and according to the facilities available to them, which are directly or indirectly related to the educational material in pursuit of the goals of the educational process (Al Fahidi, 2009).

The researcher defines it procedurally as an integrated and purposeful set of activities that the teacher uses while teaching mathematics, and works to provide students with educational experiences that differ from the experiences provided to them in the classroom. It aims to increase the students' ability to understand and deepen the subject matter, increase their achievement in mathematics, and develop their thinking. It is carried out under the supervision and guidance of the teacher.

- Educational techniques: It is the organized interaction between the human element participating in the educational process, equipment, devices and educational materials to achieve specific educational goals or solve educational problems (Sabri, 2002).

Procedurally, the researcher defines it as all multimedia educational media, and all associated materials, tools and educational programs, which the teacher employs with the third-grade students in mathematics to improve the students' academic achievement.

- Attitudes: are those responses that appear through the learner's passing through experiences and experiences that make him respond to them in terms of acceptance or rejection (Al-Maliki, 2010).

The researcher defined it procedurally as the feelings, desires, tendencies, thoughts and beliefs third-grade students showed towards mathematics by estimating its value and acceptance. This is measured by the score obtained by the student through his response on the attitude scale prepared by the researcher.

Third grade: One of the grades of the first basic stage that starts from the first basic grade, and in which the ages of students range from (6-8) years. 


\section{The Theoretical Framework of the Study}

Adopting educational technologies and paying attention to them is an inevitable necessity in light of the tangible changes and transformations that have formed reasons that require attention to them and their scientific applications. Educational technologies are useful in the field of improving the quality of education by solving the problems of overcrowding classroom, taking into account individual differences, training teachers in the field of formulating educational goals and how to achieve them, producing educational materials, choosing teaching strategies and appropriate assessment, stimulating self-learning and continuous learning among students, employing a set of means in the educational position, which works to arouse students' interest, develop their hobbies, renew their activities and participation, and satisfy their learning needs. Educational technologies make education tangible for students, promote permanent learning, make students more active, and create an enjoyable classroom environment. It reduces stereotyping, enhances teacher performance and time management, increases the effectiveness of the teaching process, and enables the learner to bring events and external phenomena into the classroom (Basar, 2014).

\section{Reasons for the Interest in using Educational Technologies}

The reasons for the interest in using educational technologies in the educational process are as indicated by (Saraya, 2007), and the most beautiful of them are as follows:

1- The rapid increase in technical and scientific growth.

2- Individuals' demand for education and the doubling of population growth.

3- The urgent need for society to prepare specialized individuals.

4- Providing non-traditional solutions to problems such as lack of motivation to learn, and low preparation of educational competencies.

5- Rapid progress in the educational field, educational strategies as a major system, and educational technologies as a sub-system thereof.

\section{Education and Mathematics Technologies}

Mathematics is an educational subject that urgently needs to employ educational technologies and programs in its teaching and learning processes. Mathematics deals with a lot of facts, concepts and abstract ideas that are difficult for students and need to be clarified, and there are many practical applications for them. When presenting facts and ideas in their abstract form, they make them difficult for students, and they see them as mere ideas and facts isolated from reality, and they cannot be seen or represented. It has no meaning for them, as it weakens their ability to imagine and understand it, and to form clear and correct images of it. Due to the importance of modern technology in teaching mathematics, the National Council of Teachers of Mathematics in America made it one of the six principles of school mathematics, which was issued in (2000), in what is known as the principles and standards of school mathematics, during which the council discussed - the principle of technology - explaining the importance of benefiting from technology in Mathematics education, because it provides the opportunity for students to focus on mathematical concepts and ideas and enhances their learning, and helps them to form perceptions of mathematical situations and ideas and see them from different perspectives at the same time, such as data, symbols and numerical representations (NCTM, 2000).

In this regard, Ghandoura (1997) pointed out that the National Council of Mathematics Teachers should emphasize the necessity of giving students the opportunity to employ and 
use educational techniques that explain mathematical concepts as the cornerstone of learning mathematics.

The use of modern technology in teaching mathematics has many positive effects, as it helped to improve students' attitudes towards learning, and increase the level of academic achievement in addition to increasing understanding and encouraging self-learning (Absi \& Abed, 2014).

\section{Teaching Techniques and Attitudes towards Mathematics}

Since the birth of a person, he has many innate motives, and when he engages in society and interacts with individuals, he/she will be affected by them. Thus, he has acquired motives, and among these motives are the attitudes that direct and affect an individual's behaviour. Thus, anything that affects an individual on the psychological and social level will be the subject of one of the psychological or social attitudes acquired by him, and accordingly, this tendency becomes negative or positive, such as the attitude towards mathematics (Abu Al-Khail, 2009).

Melhem (2005) defined the attitude as desirable or undesirable ideas and opinions, about ideas shared by a particular group.

Al-Malak (1994), Al-Harash, Fakhoury, and Yamin (2008) believe that the use of educational techniques in the educational process has an effective role in developing positive attitudes and skills among students towards the educational material, because it provides a variety of educational experiences that cannot be obtained in the usual way, and this is done by allowing each student learns according to his abilities, and gives him the opportunity to correct his mistakes without feeling ashamed or afraid. Also, the provision of enrichment activities, treatment plans and immediate feedback appropriate to him work to increase the level of his academic achievement.

\section{Literature Review}

Hajibi (2017) conducted a study that aimed to investigate the effect of teaching a mathematically computerized unit using a tablet computer in the mathematics achievement of tenth-grade female students and improving their motivation towards it. In this study, the researcher used the quasi-experimental approach, and the study sample was intentionally selected from the tenth-grade female students. To achieve the objectives of the study, the researcher calculated the statistics and probability unit from the tenth-grade mathematics book and used the achievement test, and a measure of motivation towards learning mathematics. The results of the study showed that there were statistically significant differences in the achievement of tenth-grade female students, increasing the motivation towards learning mathematics in favour of the experimental group that studied the mathematically computerized unit using the tablet computer.

Al-Zahrani (2014) conducted a study that aimed to find out the effectiveness of using the computer-assisted learning strategy in developing academic achievement, developing deductive thinking, and moving towards mathematics. The study population consisted of all fourth-grade female students in Makkah Al-Mukarramah, and the study sample consisted of (68) female students from basic schools in Makkah Al-Mukarramah. The researcher used the experimental and descriptive approach. To achieve the objectives of the study, he used the following tools: Computer-assisted learning strategies - achievement test - questionnaire. The results of the study showed the following: - The study confirmed that there are statistically significant differences for the level of the experimental group and the control group students 
in the achievement test in favour of the experimental group students. The study confirmed that there are statistically significant differences at the level of the experimental group and the control group students in the inferential thinking test in favour of the experimental group students. The study confirmed the existence of statistically significant differences in the measure of attitude towards mathematics in favour of the experimental group of students. The study confirmed that the computer is highly effective and educationally important in teaching mathematics and in developing deductive thinking and achievement.

Al-Mufleh and others (2014) conducted a study that aimed to investigate the effect of teaching using educational software in improving the level of mathematics learning motivation among basic second-grade female students in Jordan, where the researchers used the experimental method. The study sample consisted of (43) students of the second grade, who were divided into two groups: (23) of them are female students and (20) of them are male students. In order to achieve the objectives of the study, the researchers used the following tools: educational software consisting of (47) slides that include exercises and educational activities during which students learn the multiplication process, an achievement test, and a measure of motivation towards learning. The results of the study concluded that there are statistically significant differences at the significance level $(a=0.05)$ in the students' motivation level in favour of the experimental group that learned using the educational software. There are statistically significant differences in the dimensions of students' motivation to learn due to the teaching method in favour of the experimental group.

Al-Harut (2013) conducted a study aimed at investigating the effect of using the interactive board on Arabic language achievement of basic fifth graders, and their attitudes towards its use in Jordan. The researcher used the quasi-experimental approach, and the study sample consisted of (73) students of the fifth grade. They were divided into two groups: the first was the experimental group, which consisted of (39) students who studied the content of the educational material using the interactive board, and the control group, which numbered (34) students, who studied the educational material content in the usual way. The study results showed there are high trends and attitudes among fifth graders towards the use of the interactive board in favour of the experimental group.

Al-Abdali (2012) conducted a study aimed at investigating the effectiveness of using the electronic board in the achievement of fifth-grade students in mathematics and their attitudes towards it. The researcher used the quasi-experimental approach, the sample was chosen intentionally from the study population, and the study sample consisted of (43) students from the fifth grade. The researcher distributed them into two classrooms: The first grade represented the experimental group of (22) students who studied the educational material using the blackboard, and the second grade represents the control group of (21) students who were taught the educational material in the usual way. To achieve the objectives of the study, the researcher used the following tools: achievement test, and a questionnaire that measures students' attitudes towards the electronic board. The study found that the students who studied using the electronic board had higher achievement than the students who studied using the usual method. There are statistically significant differences at the significance level $(a=0.05)$ in the students' attitudes towards mathematics and in favour of the experimental group. 


\section{Study Approach}

The current study followed the descriptive and quasi-experimental approach, as it examined the effectiveness of enrichment activities program based on educational techniques in developing attitudes among third graders towards mathematics in Jordan.

\section{Study Population}

The study population consists of all third-grade students in government schools affiliated with the Directorate of Education in Jerash Governorate during the first semester of the $2019 / 2020$ academic year, who numbered $(13,500)$ male and female students, according to the statistics of the Ministry of Education for the year 2019/2020.

\section{The Sample of the Study}

The exploratory sample: An exploratory sample was chosen to test the study tools, which consisted of (25) male and female students.

Actual sample: The study sample consisted of (60) male and female students, which were chosen by the random cluster method. Table (1) shows the distribution of the study sample members.

Table (1)

It shows the distribution of the sample members for basic third-grade students

\begin{tabular}{|c|c|c|c|}
\hline Pupils' gender & $\begin{array}{c}\text { number of } \\
\text { students }\end{array}$ & School & the group \\
\hline male and female & 30 & $\begin{array}{c}\text { Mixed } \\
\text { Comprehensive } \\
\text { Muqbila High School }\end{array}$ & experimental group \\
\hline male and female & 30 & $\begin{array}{c}\text { Mixed } \\
\text { Comprehensive } \\
\text { Kefir Secondary } \\
\text { School }\end{array}$ & control group \\
\hline \multicolumn{2}{|c|}{60 male and female students } & Total \\
\hline
\end{tabular}

Study tool: To achieve the objectives of the study and to answer its questions, the researcher referred to the theoretical literature and previous studies that dealt with the subject of educational techniques and their impact on mathematics academic achievement for the basic education stage. A questionnaire was built to determine the quality standards of unit outputs collecting numbers within 9999 and subtracting them, and building a scale of third-grade students' attitudes towards mathematics.

\section{Validating the Tool Content}

To verify the validity of the study tools, the researcher, after taking advantage of the supervisor's directives, prepared the questionnaire in its initial form and came up with a list of standards, and a measure of third-grade students' attitudes towards mathematics. She presented it to a group of arbitrators, including specialists in curricula and teaching methods, specialists in mathematics and educational supervisors, specialists in the field of educational techniques, measurement and evaluation, and third-grade teachers, whose number has reached (20) arbitrators. The criterion of the agreement of seven arbitrators was based on the validity and clarity of the paragraph to remain within the tool, or on the agreement of 
three arbitrators on the lack of clarity to modify it. In light of the notes of the arbitrators, the researcher modified the questionnaire and the attitude scale and used the paragraphs agreed upon by the arbitrators.

\section{Statistical Processors}

- Arithmetic averages and standard deviations of the responses of research sample members.

- Stability coefficients (Cronbach's alpha).

\section{Displaying the Results and Discussion of the Study}

The results of the first question: What are the quality standards of unit outputs of collecting numbers within 9999 and subtracting them for third graders mathematics in Jordan?

The researcher reviewed the official documents related to the issue of developing the quality of the unit outputs of collecting numbers within 9999 and putting it into third-grade students mathematics in Jordan to determine the standards related to developing the quality of unit outputs of collecting numbers within 9999 and putting them up for mathematics through the questionnaire, and they were as follows:

The current research questionnaire was designed after the researcher reviewed the results of previous studies and research related to the research topic to formulate the theoretical framework and review the unit of collecting numbers within 9999 and subtracting it. The preparation of the questionnaire may require the following:

1- Determining the purpose of the questionnaire: The questionnaire aims in the current research to determine the quality standards for the unit outputs of collecting numbers within 9999 and putting them for third-grade students mathematics.

2- Determining the content of the questionnaire: In determining the content of the questionnaire, the researcher relied on the following:

- See the mathematics teacher's guide for the third grade.

- Analyzing the scientific content of the academic unit.

- Determining the general and procedural objectives of the mathematics unit for the thirdgrade students, then reformulating them and presenting them to the arbitrators.

- Preparing a list of the quality standards for the unit outputs of collecting numbers within 9999 and putting them in third-grade students' mathematics.

When constructing the questionnaire, the researcher took into account the following:

1- Use clear and specific goals.

2- Use paragraphs related to the topic.

3- Each paragraph of the questionnaire contain only one idea.

In light of the foregoing, the researcher reached a set of criteria to be the main criterion for developing the mathematics curriculum for the basic stage in Jordan. It included three criteria that consisted of (30) items. The first axis was cognitive criteria and included (4) items, and the second axis includes skill criteria and included (16) paragraph, and the third axis includes emotional standards and included (10) paragraphs. It should be noted that the quality standards of the unit outputs of collecting numbers within 9999 and putting it to thirdgrade students' mathematics in Jordan are characterized by the continuity of the educational reform steps undertaken by the Jordanian Ministry of Education. As a result of many basic factors that led to the interest in applying the quality of the unit outputs of collecting numbers 9999 and subtracting them, such as the weak academic level of the third-grade students in 
mathematics, and the diversity of objectives, areas, programs and quality patterns of the unit output of numbers collection within 9999 and its introduction to third-grade students mathematics in Jordan, in addition to the occurrence of economic and social changes that require individuals to possess high skills that enable them to engage in the future society.

Since the authors of the standards system for the quality of mathematics outputs, especially the third-grade mathematics, always seek to prepare students with distinctive characteristics that make them able to live with the abundance of information, the continuous change processes and the tremendous technological progress so that they can sufficiently benefit from the information to serve the learning process, especially in mathematics curriculum outcomes. It is necessary to prepare a curriculum that translates this view, and from here many researchers emphasized the importance of building new, advanced curricula in its technical and cognitive aspects integrated with multimedia so that it supports the textbook system based on a mixture of methods that combine the book, study software and the use of the Internet.

The results of the second question: What is the effectiveness of applying the proposed enrichment activities program based on educational techniques in developing students' attitudes towards mathematics in the unit of collecting numbers within 9999 and subtracting them to third graders in Jordan?

To answer this question, the researcher calculated the arithmetic averages and standard deviations of the paragraphs of the attitude scale. She also used the t-test for independent samples to find out the differences between the outputs of the experimental and control groups in the students' attitudes towards mathematics in the unit of collecting numbers within 9999 and subtracting it to the third-grade students in Jordan at the level of significance (0.05), and Table No. (2) shows this. 
Table No. (2)

Arithmetic averages and standard deviations of third-graders answers on the items of the attitude scale and for the scale as a whole

\begin{tabular}{|c|c|c|c|c|c|}
\hline $\begin{array}{l}\text { Rating } \\
\text { score }\end{array}$ & $\begin{array}{l}\text { standard } \\
\text { deviation }\end{array}$ & SMA & Paragraph & $\begin{array}{l}\text { the } \\
\text { number }\end{array}$ & Rank \\
\hline High & 0.85 & 3.98 & $\begin{array}{c}\text { The student is keen to invest } \\
\text { time during the class to solve } \\
\text { mathematical problems }\end{array}$ & 9 & 1 \\
\hline High & 0.97 & 3.9 & $\begin{array}{l}\text { The student actively } \\
\text { participates in the class }\end{array}$ & 1 & 2 \\
\hline High & 0.92 & 3.85 & $\begin{array}{l}\text { The student is keen to be } \\
\text { organized while solving } \\
\text { mathematical problems }\end{array}$ & 10 & 3 \\
\hline High & 1.17 & 3.83 & $\begin{array}{l}\text { The student is keen to } \\
\text { attend math classes }\end{array}$ & 6 & 4 \\
\hline High & 1.1 & 3.75 & $\begin{array}{l}\text { The student appreciates the } \\
\text { importance of mathematics } \\
\text { in everyday life }\end{array}$ & 5 & 5 \\
\hline High & 1.03 & 3.7 & $\begin{array}{l}\text { The student takes the } \\
\text { initiative to solve the } \\
\text { problems on the board }\end{array}$ & 2 & 6 \\
\hline Medium & 1.08 & 3.52 & $\begin{array}{c}\text { The student savours } \\
\text { mathematical beauty by } \\
\text { discovering examples and } \\
\text { patterns }\end{array}$ & 8 & 7 \\
\hline Medium & 1.21 & 3.5 & $\begin{array}{l}\text { The student shares a } \\
\text { mathematical problem with } \\
\text { his peers within the group to } \\
\text { reach the appropriate } \\
\text { solution }\end{array}$ & 4 & 8 \\
\hline Medium & 1.23 & 3.27 & $\begin{array}{c}\text { The student is excited to do } \\
\text { the homework }\end{array}$ & 7 & 9 \\
\hline Medium & 1.12 & 3.17 & $\begin{array}{l}\text { The student listens when the } \\
\text { teacher explains the } \\
\text { mathematical concepts and } \\
\text { problems }\end{array}$ & 3 & 10 \\
\hline Medium & .62 & 3.65 & \multicolumn{3}{|c|}{ the scale as a whole } \\
\hline
\end{tabular}

It is clear from Table No. (2) that the arithmetic averages of the answers of sample members to the paragraphs of the attitude scale ranged between (3.17-3.98), where paragraph (9) came in the first place, which states that "the student is keen to invest time during the session to solve mathematical problems". With an arithmetic average (3.98) and a high evaluation score, and in the tenth and last rank, paragraph (3), which states that "the student listens when the teacher explains mathematical concepts and problems" with arithmetic mean (3.17) and a medium evaluation score, and the arithmetic average of the scale as a whole is (3.65) with an average evaluation score. 
Table No. (3)

It shows the arithmetic mean, standard deviation, and $(t)$ value to indicate the differences between the outcomes of the experimental and control groups in the students' attitudes towards mathematics in the unit of collecting numbers within 9999 and subtracting them for third graders in Jordan

\begin{tabular}{|c|c|c|c|c|c|}
\hline $\begin{array}{c}\text { Statistical } \\
\text { significance }\end{array}$ & T value & $\begin{array}{c}\text { standard } \\
\text { deviation }\end{array}$ & SMA & $\begin{array}{c}\text { the } \\
\text { number }\end{array}$ & the group \\
\hline \multirow{2}{*}{.005} & -2.92 & .602 & 3.43 & 30 & control \\
\cline { 3 - 6 } & .567 & 3.87 & 30 & experimental \\
\hline
\end{tabular}

It is clear from Table No. (3) (T) test for independent samples to find out the differences between the outcomes of the experimental and control groups in the students' attitudes towards mathematics in the unit of collecting numbers within 9999 and subtracting it to the third-grade students in Jordan at the level of significance (0.05), where the results showed that there was a statistically significant difference at the level of significance $(0.05)$ between the outcomes of the experimental and control groups in the students' attitudes towards mathematics in the unit of collecting numbers within 9999 and subtracting them for the third-grade students in Jordan, where T value was (-2.92) with a statistical significance (0.005), and these differences are attributed to the experimental group with arithmetic mean (3.87) compared to the arithmetic mean of the control group (3.43).

The researcher attributes the superiority of the experimental group over the control group to those members of the experimental group that have positive attitudes towards mathematics in the unit of collecting and subtracting numbers within 9999, and that the members of the experimental group found teaching techniques more effective than the usual method, with its simplicity, clarity, and sequence in displaying Ideas, avoiding complexity, as well as taking into account their tendencies and desires, and focusing the program on highlighting the important and gradual points in education, attracting students' attention and encouraging them to continue learning the study material, and satisfying students' needs for play and fun through what the program contains in multimedia elements such as sounds, colours and moving images. The use of appropriate immediate feedback to know the student's progress, the ease of dealing with the educational program, and the use of educational techniques and not being afraid of them resulted in positive tendencies and attitudes towards learning.

The researcher also explains that the program contains many diverse enrichment activities that attract learning and are self-sufficient to which the student returns when needed, which helped them to form positive attitudes towards the study material, and the desire to deal with modern educational technologies. This would provide them with positive attitudes towards learning mathematics. Students' attitudes towards educational technologies are the new vision for learning, looking beyond the book, transcending the limits of time and space, and placing the learner in a prominent place at the centre of educational process.

The results of this study are in agreement with Hajibi study (2017); Al-Zahrani study (2014); Al-Mufleh et al. (2014); Harout study (2013), and Abdali study (2012). 


\section{Conclusion}

From the foregoing, the study concludes that certain criteria including cognitive criterion, skill criterion and emotional standards are needed toward developing the mathematics curriculum. As for quality standards, the Jordanian Ministry of Education determined it by ensuring continuity in educational reforms. Several factors such as weak academic performance, diversity in programs, areas, objectives and quality patterns, the existence of economic and social changes led to the adoption of quality of unit outputs. The study, however, proposes a comprehensive curriculum that considers and encompasses an abundance of information, encourages tremendous technological progress and continuous changing processes. The potential implication of the study is that students' educational performance will be more fruitful and productive following the curriculum amendments alongside technological advancement.

Despite the considerable inputs designed for the mathematics curriculum, there has been no rigorous empirical evidence showcasing the method of improving the curriculum toward global developments. This study fills this gap by highlighting the factors that could generate outstanding educational performance in mathematics subject. The study's results are expected to deepen understanding of the major problem triggering students' poor performance in mathematics. The study is also a wake-up call for drafters of the curriculum in developing and underdeveloped countries in embracing technological developments.

\section{Recommendations}

1. Holding courses and workshops for teachers on the importance of benefiting from the applications of educational technologies, to identify methods of employing them, selecting them, and their role in the educational process.

2. Access to studies interested in modern educational technologies to keep pace with the rapid developments in the educational field.

3. Providing enrichment programs and activities through the school curricula that meet the needs, tendencies and desires of the students at all academic levels.

4. The presence of an educational technology specialist in each school to be a reference for the teacher and the student toward employing the innovations of modern educational technologies and taking advantage of them, and to overcome the difficulties faced by teachers who wish to employ them in the educational process.

\section{References}

Abu Al-Khail, A. (2009). The educational collection and the impact of its use on students' academic achievement. Amman: Imad Al-Din for publishing and distribution.

Abu Mandeel, A. A. R. (2006). The effectiveness of using computer games in teaching some writing rules on the achievement of eighth-grade students in the Gaza Strip, an unpublished master's thesis, College of Education, Islamic University, Gaza.

Al Fahidi, R. (2009). Student Activities Guide, Kuwait: Dar Al-Urubah for Publishing and Distribution.

Al-Abdali, A. R. (2012). The effectiveness of using the smart board in fifth-grade students achievement in mathematics and their attitudes towards it in Al-Qurayyat Governorate. Master Thesis, Yarmouk University, College of Education: Jordan.

Al-Anazi, T. M. K. (2018). The degree of using educational technologies in teaching Islamic education for the intermediate stage from the teachers' point of view in the State of Kuwait. Unpublished master's thesis, Al al-Bayt University. Mafraq: Jordan. 
Al-Hiyla, M. M. (2001). The basics of designing and producing educational aids. 2nd floor, Amman: Dar Al Masirah for printing and publishing.

Al-Maliki, A. M. M. (2010). The effectiveness of a proposed training program on providing mathematics teachers with some active learning skills and on their students' achievement and attitudes towards mathematics. Umm Al-Qura University: Saudi Arabia.

Al-Molak, H. (1994). The effect of studying a computer course on tenth-grade students attitudes towards computers. An unpublished master thesis. Yarmouk University, Jordan.

Al-Zahrani, B. (2014). The effectiveness of using the computer in teaching mathematics on academic achievement and deductive thinking and the attitude towards it. Published PhD thesis, Umm Al-Qura University.

Ghandoura, A. H. (1997). Teaching mathematics with manuals, Saudi Arabia: Jeddah.

Hahibi, I. A. R. (2017). The effect of teaching a mathematically computerized unit using a tablet computer on the tenth-grade female students achievement in mathematics and improving their motivation towards learning it. PhD. International University of Islamic Sciences: Jordan.

Harut, J. H. A. (2013). The effect of using the interactive board on fifth-graders achievement in the Arabic language and their attitudes towards its use. An unpublished master thesis. University of Jordan: Jordan.

Melhem, S. M. (2005). Measurement and Evaluation in Education and Psychology, Jordan, Amman: Dar Al Masirah for Publishing and Distribution.

Sabry, M. I. (2002). The Arabic Encyclopedia of Education and Information Technology Terms. Riyadh: Al-Rushd Library for Publishing and Distribution.

Saraya, A. S. (2007). Educational technology and learning resources: theoretical concepts and practical applications. Al-Rushd Library: Saudi Arabia, Riyadh.

The Ministry of Education site. (2017). Retrieved on December 18, 2017, at http://www.moe.gov.jo/

\section{Foreign References}

Absi, M., and Abed, E. (2014). The Confidence Level of Technology Use in Learning Mathematics from class Teacher Students, Point of view and its relationship with certain variables. International Journal of Humanities and Social Science, 4(1), 179-187.

Basar, H. (2014). Class management. Memory publishing. Ankara.

Gulla, U. (2017). Implementing Blended Learning Strategies In Training Environments: Opportunities and Challenges. International Conference on Blended Learning "Towards Knowledge Economy-Saudi Electronic University- Riyadh.

National Council of Teachers of Mathematics (Nc Tm). (2000). Principles and Standers for School Mathematics Reston, VA: NCTM. 